\title{
The typography of tables: A note on L. J. Comrie.
}

Lindsay Rollo

Astronomers and those interested in machine computing honour Comrie for his work in these fields. They join typographers and elderly mariners in honouring him for his contribution to the typography of tables.

Leslie John Comrie was born in Pukekohe in 1893. He graduated MA Hons in chemistry in 1916 from Auckland University College. 'In spite of his deafness, he served in the New Zealand Expeditionary Force in the First World War, and ... was wounded, losing a leg' (Greaves, 296). Prestigious scholarships and studentships led to a PhD at Cambridge where he studied astronomy. After a period at Cambridge, and then teaching in the United States where he introduced a course in computational science, Comrie returned to Britain in 1925 to an appointment to H.M. Nautical Almanac Office, becoming Superintendent in 1930. He resigned in 1936 and the following year founded Scientific Computing Service Ltd, which provided 'major computational operations for government departments, for universities, and for industry.'

Comrie was particularly proud, and justifiably so, of the war work of his firm. Three hours after war was declared he was approached by the War Office who required, as a matter of urgency, some ballistic tables. The work was planned and begun within 24 hours and two volumes of 200 pages of double entry pages were computed, set, printed, indexed and bound, all in the first twelve days of the war (Greaves, 300).

It is hard for those who have only known pocket calculators or computers and laser printers as the vehicles for computation to recognise the truly immense volume of manual work involved in keyboarding the entries, the pedestrian speed and distracting noisiness of pre-War mechanical computing machines, the subsequent re-keyboarding of the type for printing, and the mind-numbing attention to details required in checking the page proofs of all types of extended tables.

Unlike text proofing, where most words can be checked at a glance, tables have to be checked character by character. For example, many pages of the Nautical Almanac ${ }^{1}$ had some 3400 individual alphanumerical characters, each of which had to be calculated, checked, then keyboarded for typesetting, and 
finally page proofed before printing. It was to be another twenty years before robust computer programs with advanced mathematical formulae became readily available for producing accurate results and seriously reducing the tedium of this type of activity.

Obituaries of Comrie all refer to both the accuracy and the clarity of his tables and to his expert knowledge of typography. It has not been possible to determine how he developed his typographical expertise. Nor is it known if he was familiar with any of the peer-reviewed research and other papers about the legibility of specialist books and tables published between 1917 and 1930 and referred to in Tinker's 1954 paper Readability of Mathematical Tables.

However, the period when he first became directly involved in, and then responsible for the publication of tables - the mid 1920s to early 1930s —was a period of considerable typographic debate and innovation; largely Londonbased, it was characterised in Britain by such publications as The Fleuron and the Penrose Annual, the promotion of new and re-cut fonts by the Monotype Corporation, and the work of Stanley Morison in revising the typography of The Times. For someone passionate about excellence, it seems unlikely that Comrie could have been ignorant of either the debate or the technology. Indeed, he expressed generous appreciation of the work and skills of Monotype typesetting operators and compositors in the preparation of his tables.

His understanding of the type and typesetting practice is well illustrated in just over five quarto pages (numbered 14-19) of the typography notes and comments offered to W \& R Chambers Ltd in a proposal he put forward 'in 1944 for a new, seven-figure, edition of Chambers's Tables, originally published in 1878' (Schwarz).

He discusses the style of figure [numerals]; which of the Monotype types best suits the purpose; measure, paper size, and leading; grouping of lines; rules; and a number of other points specifically related to the tables' content and use. Throughout, the notes display a clear understanding of the practical issues involved in achieving both legibility and the avoidance of proofing errors induced by hand composing.

Of the use of rules he said:

A profusion of rules defeats its own purpose, and blackens the page too much. If the page is going to be squeezed, rules are necessary to guide the eye, but a more pleasing effect can often be secured by judicious use of spacing. ... Rules (including border rules) are a help to the printer in keeping type straight (as are also full-measure leads). If they are abandoned, as I believe they could be with profit,

Kōtare 4, no. 1 (2001), pp. 21-31. 
great care must be taken to get the type straight before the plates are made. (Schwarz)

Of more interest are his declarations of objectives. The opening paragraph of the Chambers proposal section, headed 'Typography', reads:

Before discussing in detail the tables proposed, it is essential to ask how they will be printed. Too often neither the editor nor the publisher is proficient in table typography (which is quite different from that of textbooks) and "leaves it to the printer", with disastrous results, because invariably the printer will study his own convenience rather than that of the user [author's emphasis]. Of the four people concerned with the book - author, publisher, printer and user-it is the latter whose interest should predominate, subject to the sordid necessity that none of the first three (except the author!) should be out of pocket. Users can "get used" to inferior typography, but there is no reason for offering it to them. In general good printing costs no more than bad, since a compositor taps keys impersonally to set figures, a casting machine takes as long and costs as much whatever matrices are used, and the printing machine is not conscious of the lay-out that it is reproducing. The art lies in the instructions to the printer.

Comrie's concern for the end user echoes Morison's definition of typography published in The Fleuron No.7 (1930) as

the craft of rightly disposing printing materials in accordance with a specific purpose: of so arranging the letters, distributing the space and controlling the type as to aid to the maximum the reader's comprehension of the text.

Comrie might have added 'or table' to the sentence.

Comrie's 1944 typescript proposal states 'It was established a century ago by Babbage and De Morgan that Old Style figures (sometimes called head-andtail figures) [see Fig. 1] are superior to modern face figures [see Fig. 2, following page] for mathematical tables. This conclusion has never been challenged, and I am wholly in agreement with it.'

Comrie is referring to the Preface $^{2}$ of the 1827 edition of

Kōtare 4, no. 1 (2001), pp. 21-31. 


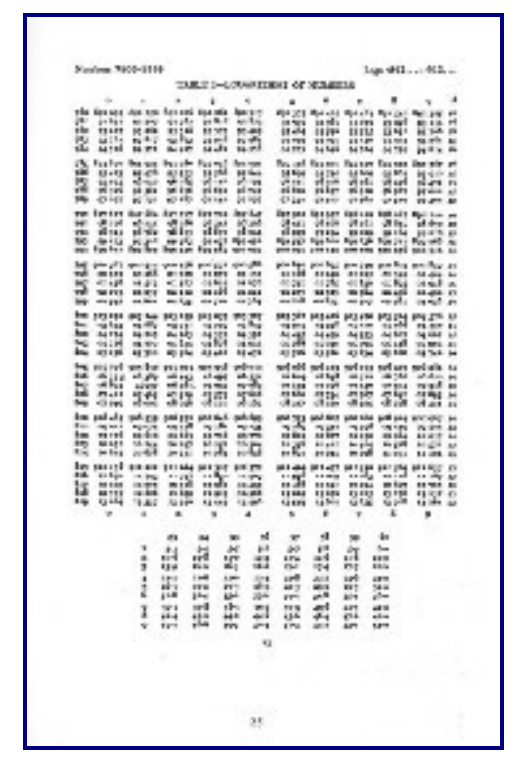

Fig. 1: A portion of an example of Comrie's skill as a table maker, with old style numerals. Tabular material displayed without rules and using space to break up long columns of data. Spaces also help guide the eye across the page and facilitate faster identification of the intermediate values within the five-line groups (Comrie, 23).

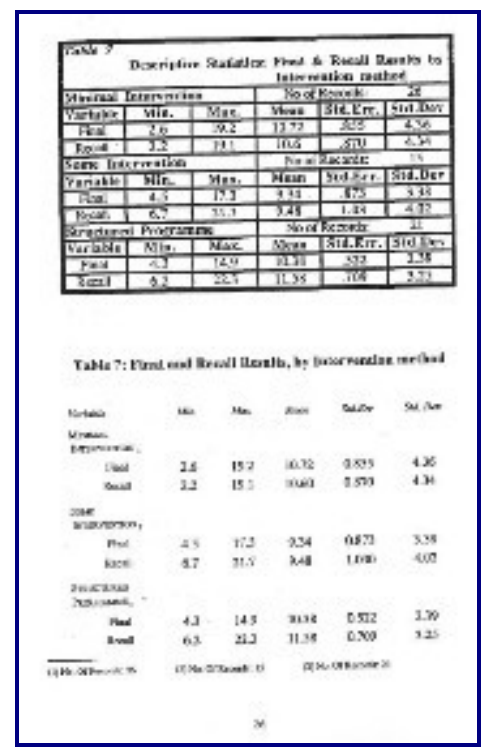

Fig. 2. These examples demonstrate the dangers of using computer program default settings for displaying tables, and what can be achieved with minimal lines and limited typographical cues. [Author's reworking of data.] In the reworked example, note also that the figures in the body of the table are set 2 points larger then the table's legends and column labels. [Original example, Ferguson, 30.] 
Babbage's Tables of Logarithms, and to an 1842 item by De Morgan. Babbage's Preface (vii) recorded that he and a Lt Col Colby [a military engineer], 'examined a considerable collection of tables, with a view of discovering on what typographical circumstances perspicuity depended.' Their first two (of fifteen) rules were:

The clearness, or facility of reading, does not depend on the size of the type alone, but on the proportion of the type to the interval between the lines.

Figures of the same height, or nearly the same height, are preferable to those in which some of the digits rise above and others fall below the line, because they interfere less with the space between the lines.

The first rule notes the importance of the interlinear spacing (formerly known as leading), and the second rule has been interpreted as suggesting a preference for 'modern' aligning numerals in contrast to 'old style' non-aligning numerals.

De Morgan's views are recorded in an entry about 'table' in the Penny Cyclopedia, 1842 (497). His comments are based on opinions of table users, and strongly support the use of 'old style' numerals with unexaggerated stroke characteristics 'and their decided superiority... is pretty generally admitted.' De Morgan specifically rejected the use of 'modern' numerals.

In both these sets of subjective assessments, it must be rioted that the fonts they were viewing had most probably been produced by manual methods, and were therefore subject to much variability and were frequently of indifferent design, and may also have been worn by much use. It was about the mid 19th century before the advent of accurate repeatability by machine manufacture could guarantee identical type characters, and reduce the cost sufficiently to allow a fresh font to be used for major projects.

In the preface to the 1950 edition of Chambers's Shorter Six-Figure Mathematical Tables, Comrie states that 'De Morgan clearly demonstrated the superiority of "old style" figures with heads and tails over so-called "modern" or equal height figures for mathematical tables'.

Two things should be noted about the 1944 and 1950 statements. First, in the 1944 proposal, Comrie clearly failed to recognise that the Babbage and De Morgan subjective assessments were diametrically opposed (as can be seen from the second of Babbage's rules quoted above). In the 1950 preface he drops the reference to Babbage.

Kōtare 4, no. 1 (2001), pp. 21-31. 
Secondly, in the 1944 proposal the words 'It was established a century ago' imply a much more disciplined determination of the preference for 'old style' figures than was in fact the case. Equally, in the 1950 preface, Comrie's statement 'De Morgan clearly demonstrated the superiority of "old style" figures' also carries an implication of structured research rather than the subjective judgements offered by both Babbage and Colby, and by De Morgan. This is an atypical lapse by a man noted in his obituaries in several learned society journals as 'characterised by an essential simplicity of approach, supplemented by an implacable computing technique in which the greatest attention is paid to detail' (Greaves, 299).

Comrie's and Babbage's recognition of the importance of the visual aspects of table use are echoed in work undertaken by Tinker (436-42). Speed and accuracy of use were the criteria for assessment in experiments with 120 adult university students, in a laboratory room with uniform lighting, and using samples that compared, amongst other features, type face, type size, and leading between groupings of entries down the columns. The results 'revealed certain typographical factors which promote more effective readability as well as certain conditions that should be avoided'(442). As a result of the experiments, he suggested: tables should not be crowded with too many columns; limit a page to about 50 entries per column; use at least 8 point type, either old style or a modern face; employ generous leading to separate numerals into groups of five down columns ...; use at least 1 pica space between columns without rules; use bold face in the number column; use paper thick enough so that the shadows from the print on the reverse side of the page do not show through; use mat[t] white paper and jet black ink to assure maximum contrast between ink and paper.

There is little here that Comrie would have disputed, even though he had a preference for old style characters.

It is ironic that when the Nautical Almanac became a joint UK / US publication in 1960, the British section displayed old style numerals and the American section modern numbers. From 1980, the joint series is displayed entirely with modern numerals and, in the author's opinion, many more rules than Comrie would have approved of or used.

Although books of tables have generally been superseded by computers, the legibility of computer-generated tables commonly leaves much to be desired, and appears to be a neglected aspect of their use.

The default settings in flagship word processors and spreadsheets frequently produce some singularly ugly results, whereas, with a little thought and effort, acceptable if not excellent tables are possible.

Kōtare 4, no. 1 (2001), pp. 21-31. 
Virtually all fonts bundled with software programs provide only aligning numerals, although non-aligning numerals are available as options in a few fonts and in the so-called expert set fonts and OpenType fonts. Tinker's work shows that this particular point is not paramount in creating good tables. The spatial arrangement of the table is at least as important, if not more important, for ease and rapidity of use and accuracy of interpretation or transcription.

Jan Tschichold, the type designer, has commented (Tufte, 55): The setting of tables, often approached with gloom, may with careful thought be turned into work with great pleasure. First, try to do without rules altogether. They should be used only when necessary. Vertical rules are needed only when the space between the columns is so narrow that mistakes could occur in reading without rules. Tables without rules look better; thin rules are better than thick ones.

These simple prescriptions for making readable tables seems to have been overlooked by both the software programmers and the tutors of computing studies in schools and universities (again, see Fig. 2 on p. 26).

Examination of the many tables Comrie constructed or edited shows clearly that his judgement and the received wisdom on which he based his practice were sound and executed with great skill and care to make them both extremely accurate and highly legible.

\section{Works Cited:}

- Babbage, Charles. Table of Logarithms of Natural Numbers. London: E \& F N Spon, 1872 [stereotyped edition incorporating the Preface to the original 1827 edition].

- Comrie, L.J. Chambers Shorter Six-figure Mathematical Tables. Edinburgh: W \& R Chambers, 1972.

- De Morgan, Augustus. Penny Cyclopedia. London: C. Knight, 1842.

- Ferguson, J. Final Report: Exploratory Studies in Curriculum Innovation: Keyboard Skills. Wellington: Wellington College of Education, undated [1993?].

- Greaves, W.H.M. 'Obituary Notices — Leslie John Comrie.' Monthly Notices of the Royal Astronomical Society, Vol.113,1953.

- Schwarz, Catherine (Senior Reference Editor), W \& R Chambers, Edinburgh 1987, Personal Communication.

- Tinker, Miles A. 'Readability of Mathematical Tables.' \}oumal of Applied Psychology 1954 Vol. 38 (6) 436-42.

- Tufte, Edward R. Envisioning Information. Cheshire: Graphic Press 1990.

Kōtare 4, no. 1 (2001), pp. 21-31. 


\section{Endnotes}

1 The Nautical Almanac is the direct linear successor of tables issued 17671831 by the Commissioners of Longitude; 1832-1959 by the Lord Commissioners of the Admiralty; 1960 jointly by $\mathrm{H}$. M. Nautical Almanac Office and the Nautical Almanac Office, US Naval Observatory.

2 I am grateful to Garry J Tee of Auckland University who kindly provided a photocopy of the Preface and other papers relating to Babbage and Comrie.

Kōtare 4, no. 1 (2001), pp. 21-31. 